\title{
The Distribution of Calmodulin in Living Mitotic Cells
}

\author{
MICHAEL ZAVORTINK, ${ }^{1}$ MICHAEL J. WELSH, ${ }^{2}$ \\ and J. RICHARD McINTOSH ${ }^{1, *}$ \\ ${ }^{1}$ Department of Molecular, Cellular and Developmental Biology, University of Colorado, Boulder, \\ CO 80309 and ${ }^{2}$ Department of Anatomy and Cell Biology, School of Medicine, \\ University of Michigan, Ann Arbor, MI 48109, USA
}

\begin{abstract}
Calmodulin has been labeled with rhodamine isothiocyanate (CaM-RITC) and used as a probe for the location of calmodulin in vivo. CaM-RITC retains its capacity to regulate the activity of brain phosphodiesterase in a $\mathrm{Ca}^{2+}$-dependent manner in vitro, indicating that the labeled protein is still active. After injection into living mammalian cells CaM-RITC incorporates rapidly into the mitotic spindle; the details of its localization there mimic closely the distribution of calmodulin seen by immunofluorescence. In interphase cells the CaM-RITC is excluded from the nucleus, but shows no region of specific concentration within the cytoplasm. Neither a 2-fold increase in cellular CaM nor the injection of anti $\mathrm{CaM}$ has any observable effect on the progress of mitosis.
\end{abstract}

Calmodulin (CaM) is a heat-stable, calcium-binding protein which has been found in all eukaryotic cells so far examined. The protein mediates effects of calcium ions on many cellular events $[1,2,3]$. Calmodulin has been localized by indirect immunofluorescence to the mitotic apparatus (MA) in several types of mitotic cells $[4,5]$. In metaphase and anaphase, this localization is to the coldstable, kinetochore microtubules (MTs) of fixed cells, suggesting that CaM might be involved in the regulation of the movement of chromosomes to the poles [6]. It has been proposed that calmodulin might control the effects of endogenous calcium on spindle microtubule stability [4-6]. Indeed experiments concerning the effects of $\mathrm{Ca}^{2+}$ and $\mathrm{CaM}$ on cold labile brain MT assembly/disassembly in vitro have supported this idea [7]. Further, the tau factors, one of the major groups of MT-associated proteins which affect the assembly of MTs in vitro, have more recently been identified as CaM-binding proteins $[8,9]$. Other laboratories have extended these observations concerning $\mathrm{CaM}$ and $\mathrm{Ca}^{2+}$ regulation of in vitro MT assembly by showing that cold stable MTs from brain can be made cold sensitive by a CaM and $\mathrm{Ca}^{2+}$-dependent process [10]. On the other hand, as more components of the mitotic spindle are characterized and the involvement of $\mathrm{CaM}$ in other structural or motile systems is detailed, other possible roles for spindle CaM emerge. CaM has been identified as a regulator for the activity of myosin light chain kinase [11, 12], an enzyme that controls contraction of smooth muscle. This enzyme has recently been identified by immunocytochemistry as a

* To whom offprint requests should be sent. 
spindle component [13]. Given the association of $\mathrm{CaM}$ with proteins of the cell cortex [14], actin-binding proteins [15] and cilia [16, 17] one cannot readily infer a role for CaM during mitosis simply from its localization.

In an effort designed ultimately to examine the proteins associated with $\mathrm{CaM}$ during mitosis we have chosen to study the behavior of CaM in living mitotic cells and thereby to define the affinity of CaM for the various cellular locations which have been attributed to it. Hamaguchi \& Iwasa [18] first demonstrated the feasibility of using fluorochrome-modified CaM microinjected into fertilized sea urchin eggs to study the in vivo behavior of the protein. However, the fluorochrome they used, $N$-(7-dimethylamino-4-methyl courmauryl)-maleimide (DACM), is restricted in its use in vivo because of the short wavelength light needed for excitation. In this paper we report the use of a biochemically active CaM-tetramethylrhodamine isothiocyanate (CaM-RITC) conjugate $[19,20]$ which avoids the spectral problem of DACM labeling. We have microinjected our fluorescent derivative into living mammalian cells, strains PtK, BS-C-1, and 3T3, using both micropipet and erythrocyte-mediated microinjection. We have obtained results concerning both the location of CaM-RITC in vivo and the effects on the behavior of living cells of changing the endogenous concentrations of CaM.

\section{MATERIALS AND METHODS}

\section{Microinjection}

Direct needle injection was performed as described by Graessman et al. [21] using $1 \mathrm{~mm}$ glass capillaries (W-P Instrument Co) shaped with a Sutter Instrument Co. model P-77 pipet puller to form needles with an outside tip diameter less than $0.5 \mu \mathrm{m}$. The needles were loaded through their back ends by capillary action. They were positioned with a Leitz micromanipulator over cells grown on coverslips, using a $40 \times$ water immersion phase lens and a Zeiss Universal microscope to view both cells and needles. Injection was accomplished by applying pressure to a $50 \mathrm{ml}$ syringe connected to the needle while simultaneously lowering the needle into the cytoplasm. Proteins were injected in a solution containing $140 \mathrm{mM} \mathrm{K}^{+}, 100 \mathrm{mM}$ glutamic acid, $40 \mathrm{mM}$ citric acid, $1 \mathrm{mM} \mathrm{MgCl}$, and $1 \mathrm{mM}$ ethylene glycol bis( $\beta$-aminoethyl ether)- $N, N, N^{\prime}, N^{\prime}$-tetraacetate (EGTA) at a $\mathrm{pH}$ of 7.2, a buffer developed for tubulin injections. We have also used phosphate buffered saline (PBS) pH 7.4 and 0.125 $\mathrm{M}$ sodium borate $\mathrm{pH} 8.5$ with no apparent differences in the behavior of either the cells or the CaM. Protein concentrations varied from 0.1 to $1 \mathrm{mg} / \mathrm{ml}$ for calmodulin, and from 0.1 to $5 \mathrm{mg} / \mathrm{ml}$ for fluorescently labeled bovine serum albumin (BSA), ovalbumin, or cytochrome $c$.

The average volume injected with this technique was determined by injecting ${ }^{125}$ I-BSA (prepared using lactoperoxidase [22]) into a total of $4000 \mathrm{PtK}$ cells or $2000 \mathrm{BS}-\mathrm{C}$ cells, rinsing to remove external ${ }^{125} \mathrm{I}$-BSA, and counting in a liquid scintillation counter. By this method, we estimated that cells received an average injection of $1-2 \times 10^{-13}$ liter: $10 \%$ of the cell's volume.

Erythrocyte ghost-mediated microinjection was done using established procedures [23] and a CaMRITC concentration of $1 \mathrm{mg} / \mathrm{ml}$ at the red blood cell loading step. Sendai virus used for the fusions was a generous gift of Dr M. Rechsteiner, University of Utah. Similar loadings of red blood cells with ${ }^{125}$ I-CaM gave loading efficiencies of $25-30 \%$, so we estimate that the amount of CaM delivered to the tissue culture cells was comparable in magnitude to that achieved in the direct needle injections.

\section{Microscopy}

Cells were observed during and immediately after injection with the water immersion lens. To facilitate long-term observations with better optics, coverslips containing injected cells were inverted 

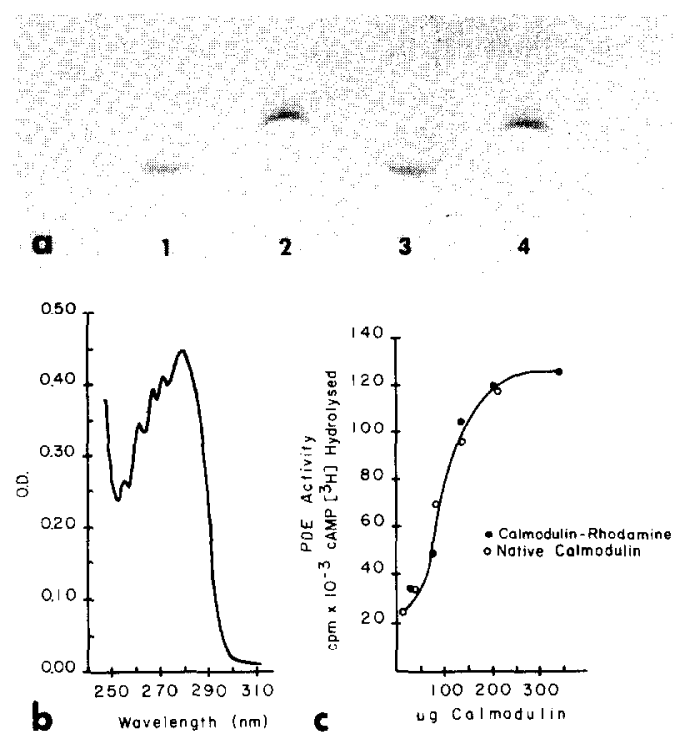

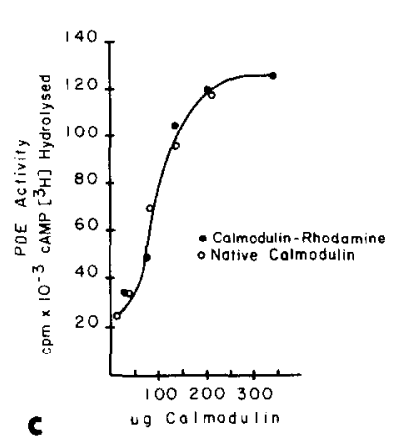

Fig. 1. Characterization of calmodulin-rhodamine conjugate. (a) SDS polyacrylamide slab gel of CaM-RITC in 1 with $\mathrm{Ca}^{2+} ; 2$, with EGTA; native calmodulin in 3 with $\mathrm{Ca}^{2+} ; 4$, with EGTA. (b) Ultraviolet absorption spectrum of native calmodulin used for rhodamine conjugation. (c) Activation of calmodulin-deficient bovine brain phosphodiesterase (PDE) by native and rhodamine-conjugated calmodulin.

on a microscope slide in PBS using coverslip fragments as spacers between the coverslip and slide, and then sealed with a mixture of parafin, petroleum jelly, and lanolin $(1: 1: 1)$. The microscope stage temperature was kept at $37^{\circ} \mathrm{C}$ with a Sage air curtain incubator during both injection and observation.

Photographs of injected cells were made on a Zeiss microscope using Plus X film and developed in Kodak HC 110 dilution B for fine-grain negatives at ASA 800. Exposure times varied from $30 \mathrm{sec}$ to 2 min. Alternatively, cells were observed using a Venus DV-2 image-intensified video camera and recorded in time-lapse or real time with a video tape recorder. Still photographs from the moving video tape were made with a Nikon camera and Pan X film using $1 / 8-1 / 2$ sec exposures.

\section{Protein Preparation and Labeling}

Bovine serum albumin (BSA), cytochrome $c$, and ovalbumin (all purchased from Sigma) were labeled with either fluorescein isothiocyanate (FITC, from Sigma) or tetramethyl rhodamine isothiocyanate (RMRITC, from Research Organics) in pH 9 PBS, using a fluorochrome-to-protein molar ratio of $4: 1$. After $4 \mathrm{~h}$ at $4^{\circ} \mathrm{C}$, unbound fluorochrome was removed by extensive dialysis. SDS gel electrophoresis indicated that all of the remaining fluorochrome was bound to the protein. $\mathrm{CaM}$ was iodinated following published procedures [24] using Bolton-Hunter reagent purchased from New England Nuclear Corp.

Calmodulin was purified from bovine testes by the method of Dedman et al. [25] and was conjugated with TMRITC as described by Welsh et al. [20]. The protein used for TMRITC conjugation was confirmed to be calmodulin by its ultraviolet absorption spectrum, its electrophoretic mobility in SDS polyacrylamide gels in the presence of $\mathrm{Ca}^{2+}$ or EGTA, and its ability to activate calmodulin-deficient bovine brain phosphodiesterase [26].

Heat-inactivated CaM was prepared by boiling CaM-RITC in a pH 12 solution of PBS for 15 min followed by dialysis to lower the $\mathrm{pH}$ to 7.0. After this treatment, the majority of the $\mathrm{CaM}$ retained its rhodamine label, and comigrated as a somewhat broader band with CaM-RITC. CaM inactivated in this way is unable to activate calmodulin-deficient bovine brain phosphodiesterase [27].

Fluorochrome to protein ratios were determined by measuring the visible light absorbed by each conjugate and by standard colorimetric protein estimation. Dye molarity was estimated using free dye extinction coefficients of $7.4 \times 10^{4}$ at $495 \mathrm{~nm}$ for fluorescein and $2.4 \times 10^{4}$ at $555 \mathrm{~nm}$ for rhodamine $[28$, 29]; protein mass was determined by the method of Bradford [30]. Typical fluorochrome: protein molar ratios varied from 0.23 for rhodamine-labeled BSA to 1.0 for fluorescein BSA. 

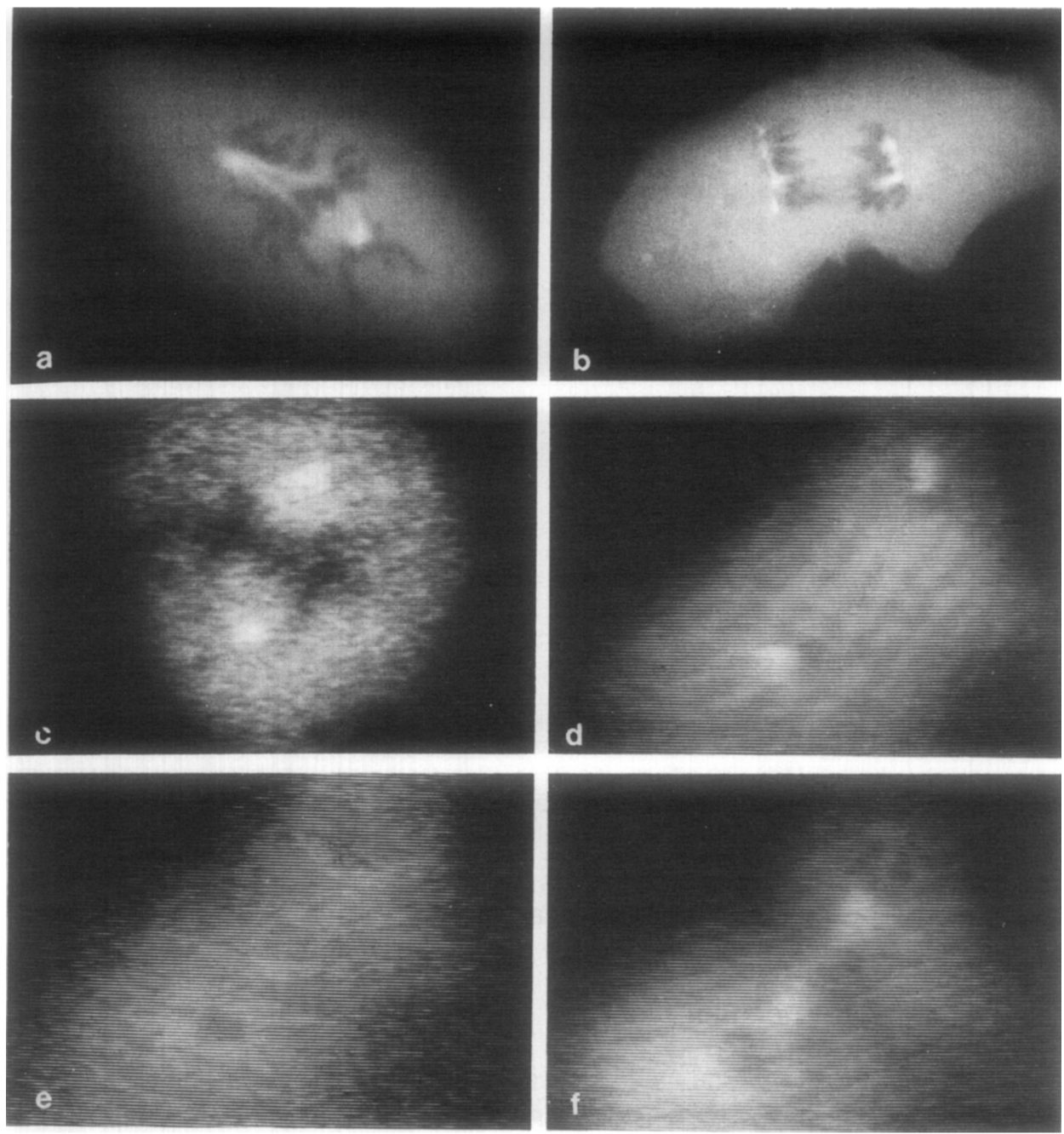

Fig. 2. Distribution of CaM-RITC in mitotic PtK cells. (a) Prometaphase, 10 min post-injection; (b) anaphase, 25 min nost-injection in the same cell as shown in (a), photographed on plus-X film. $(c-f)$ Video time-lapse recording of the same cell during $(c)$ metaphase; $(d, e)$ late anaphase; $(f)$ telophase at $2,13,21$ and $29 \mathrm{~min}$ post-injection, respectively. $(a, b) \times 1600 ;(c-f) \times 2400$.

\section{Cell Culture}

The rat kangaroo cell line (PtK1) African green monkey kidney cells (BS-C-1), human cells (HeLa), and mouse 3T3 cells were grown as previously described [31]. Large numbers of mitotic cells for use in the RBC-mediated microinjections were gathered by mechanically dislodging the rounded cells $5 \mathrm{~h}$ after release from a $24 \mathrm{~h}$ exposure to medium supplemented with $1 \mathrm{mM}$ thymidine.

\section{Anti-Calmodulin}

Antibodies against bovine testis calmodulin were raised in sheep, using performic acid-oxidized CaM, essentially as described by Van Eldik \& Watterson for the production of rabbit anticalmodulin [32]. 


\section{RESULTS}

\section{Characterization of CaM-RITC}

CaM used for the synthesis of CaM-RITC showed the characteristic ultraviolet absorption spectrum (fig. 1 b), indicating that the protein was indeed CaM [33, 34]. SDS gel electrophoresis followed by silver staining indicated that the $\mathrm{CaM}$ was homogeneous. Calmodulin labeled with TMRITC was found to have calcium- and EGTA-dependent mobilities on SDS gels, identical to those of unmodified CaM (fig. 1 a). Furthermore the fluorochrome-modified CaM was found to activate CaM-deficient bovine brain phosphodiesterase in a dose- and calciumdependent manner, identical to that of unmodified protein (fig. $1 c$ ). These tests indicate that the CaM-RITC should be suitable as an in vivo substitute for endogenous CaM.

\section{CaM-RITC Microinjection into Living Cells}

When CaM-RITC was microinjected into mitotic PtK cells via the direct micropipette method, the fluorescent $\mathrm{CaM}$ conjugate was seen to diffuse rapidly throughout the cell cytoplasm. An accumulation of the fluorescent protein in the spindle could be seen within a few seconds after injection. This rapid recruitment of CaM-RITC into the mitotic apparatus was observed, regardless of the stage of mitosis at which the protein was injected. At prometaphase and metaphase, CaMRITC became located predominantly near the poles of the spindle (fig. $2 a$ ). In early anaphase, fluorescence was confined to the space between chromosomes and poles (fig. $2 b$ ). In late anaphase, the fluorescence was also concentrated in the interzone region. CaM injected at either 0.1 or $1 \mathrm{mg} / \mathrm{ml}$ in the needle gave qualitatively identical results. Once concentrated in the spindle, CaM-RITC persisted there through telophase, allowing the changes in localization to be followed in individual cells. Prolonged observations with bright $546 \mathrm{~nm}$ light, however, increased the incidence of chromosomal non-disjunction. Long-term observations were therefore conducted with phase contrast optics using dim light, interrupted with brief visualizations of the CaM-RITC by epifluorescence. A total of 5-7 min viewing with $546 \mathrm{~nm}$ light by epifluorescence had no visibly deleterious effects on the cells. By following one cell through time we confirmed that a single cell will show the multiple localizations of spindle $\mathrm{CaM}$ (fig. $2 c-f$ ) as described for fixed mitotic cells by immunofluorescence [4-6].

The concentration of fluorescent protein into the mitotic apparatus was observed only with biochemically active CaM-RITC (fig. 3). CaM-RITC inactivated by elevated temperature at alkaline $\mathrm{pH}$ failed to concentrate in any portion of mitotic or interphase cells (fig. $3 b$ ). Likewise, BSA-RITC, BSA-FITC, cytochrome $c$-RITC, and ovalbumin-RITC all distributed evenly through the cytoplasm of mitotic cells, with no concentration or sticking occurring in the spindle (fig. 3).

No specific localization for CaM was seen in interphase cells, either immediately following injection or when viewed up to $24 \mathrm{~h}$ after injection (fig. 4). The 

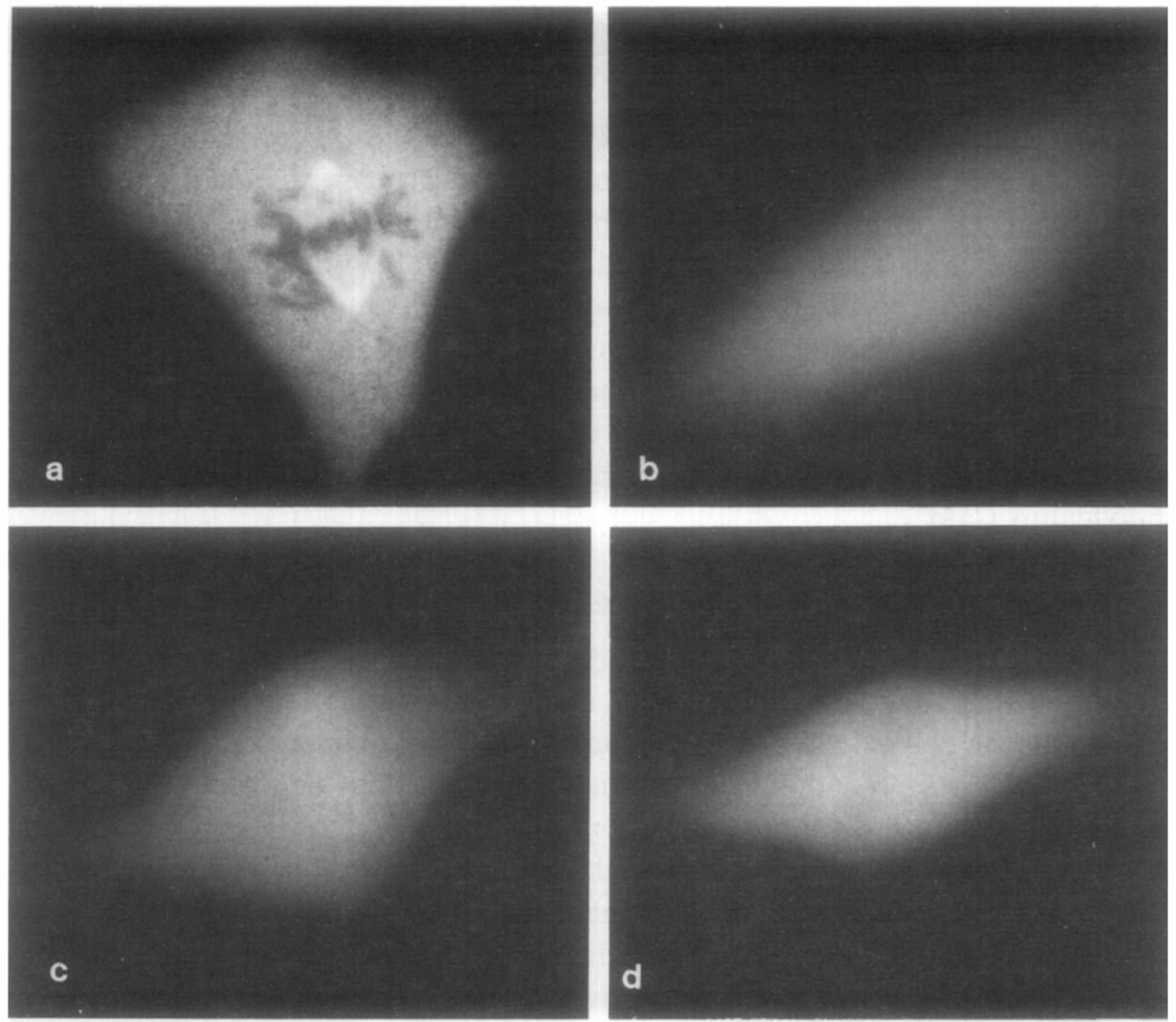

Fig. 3. Specificity of CaM-RITC localization in metaphase PtK cells. (a) Biochemically active CaMRITC; $(b)$ inactive CaM-RITC; $(c)$ BSA-RITC; $(d)$ cytochrome $c$-RITC. $(a, c) \times 1600 ;(b) \times 1000$.

CaM-RITC did, however, retain its ability to be localized specifically, since cells entering mitosis $24 \mathrm{~h}$ after injection showed CaM-RITC concentrated in their spindles (fig. $4 c$ ). A small fraction of the fluorescence in these cells is localized in small spheres, suggesting that the injected $\mathrm{CaM}$ is bcing turned over by the catabolic systems of the cell (fig. 4) [35].

CaM-RITC microinjected into living HeLa cells by fusion with loaded red blood cell ghosts showed a distribution of fluorescence essentially identical to that observed for CaM-RITC injected by needles into PtK cells, taking into account the differences in spindle morphology between the two cell types (fig. 5). We also visualized the location of $\mathrm{CaM}$ in vivo by needle injecting PtK cells with affinity-purified, sheep anti-CaM at a concentration of $9.6 \mathrm{mg} / \mathrm{ml}$ in the needle (fig. 6). These cells were fixed for immunofluorescence 10-20 min after injection and stained with fluorescein-labeled rabbit anti-sheep IgG. The location of fluorescence was essentially identical to that seen here with CaM-RITC and similar to that previously described by conventional indirect immunofluorescence with 

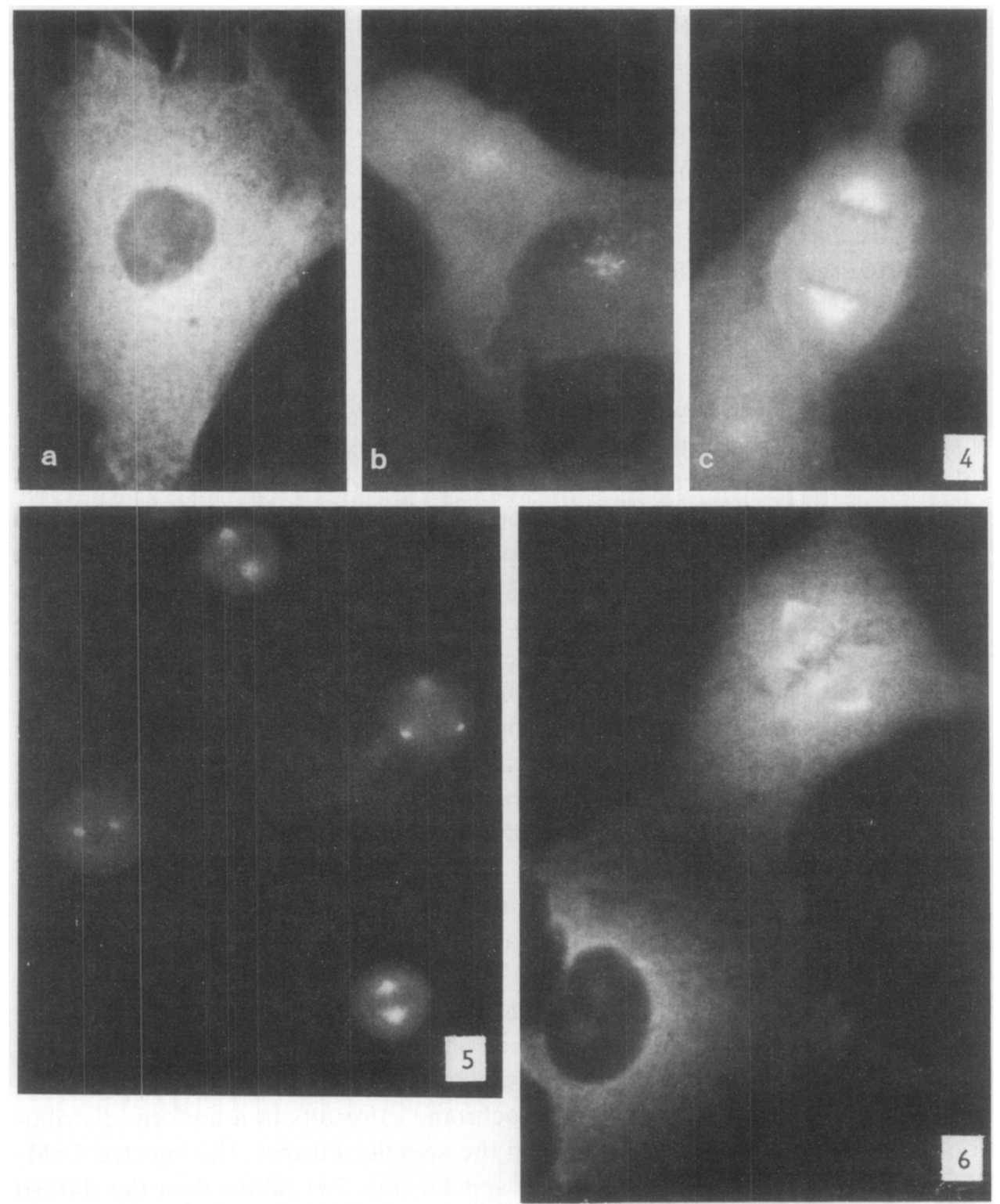

Fig. 4. Localization of CaM-RITC in B-SC cells $10 \mathrm{~min}$ and $25 \mathrm{~h}$ after microinjection with CaM-RITC. (a) Interphase cell $10 \mathrm{~min}$ post-injection; (b) interphase cells; (c) anaphase cell $25 \mathrm{~h}$ post-injection. $\times 1600$.

Fig. 5. Erythrocyte-mediated microinjection of CaM-RITC into HeLa cells. $\times 600$.

Fig. 6. Microinjection of calmodulin antibody into a mitotic and an interphase PtK cell. Cells were microinjected with affinity-purified sheep anti-calmodulin, fixed in formalin $10 \mathrm{~min}$ after injection and permeabilized with cold acetone. The cells were then incubated with fluorescein conjugated rabbit anti-sheep IgG to localize injected antibody. In interphase, the immunoglobulin was distributed evenly throughout the cytoplasm but was excluded from the nucleus. During mitosis, antibodies were found associated with the mitotic apparatus in a pattern similar to that seen with CaM-RITC. $\times 1600$. 


\section{Zawortink et al.}

the same antibody, except that the injected antibody showed no staining of stress fibers (fig. 6).

Cells injected with excess CaM-RITC or anti-CaM antibody were not noticeably perturbed by the injections. $87 \%$ of mitotic cells injected with sufficient antibody to bind roughly all of the endogenous CaM were found as pairs of daughter cells 90 min after injection (66/76 cells). In our hands, typically $85-100 \%$ of mitotic cells injected with BSA or other control proteins finish mitosis successfully during this time period.

\section{DISCUSSION}

Our results provide new evidence confirming previous observations that CaM is specifically located in the mitotic spindle. By using CaM-RITC, we have been able to follow CaM localization in vivo and obviate some of the potential problems characteristic of immunofluorescence. There are, however, potential pitfalls in the method used here, and appropriate controls for these difficulties are essential. Pardue et al. [19] labeled CaM with RITC, showing that it could remain functional, but that some preparations of CaM-RITC lost their $\mathrm{Ca}^{+}$-dependent shift in mobility on SDS gels and their capacity to activate phosphodiesterase. It was therefore critical to demonstrate that the CaM-RITC used was active. The phosphodiesterase assay we have employed demonstrates that our modified CaM can both bind calcium and bind to an enzyme it is known to regulate. While one can never prove that a modified protein is indistinguishable from its unmodified form, these two significant properties of a functional CaM have been retained by our fluorochrome-labeled protein.

It is also important to rule out a number of potential artefacts which could account for the observed localization of CaM-RITC in the spindles of injected cells [36, 37, 38]. For example, Wang \& Taylor [39] have found that in sea urchin blastomeres, injected proteins are often excluded from the yolk-rich cytoplasm and so are concentrated in the spindle region. Such behavior cannot account for our observations on tissue culture cells, since the injection of a variety of nonspindle proteins (BSA, ovalbumin, cytochrome $c$ ) results in a uniform distribution throughout both the cytoplasm and the spindle. Further, the injected CaMRITC has a fibrous appearance in the spindle (fig. $2 a$ ) rather than the diffuse localization seen for control proteins in sea urchin embryos [33]. Finally, the localization of CaM-RITC in the spindle is seen only with functional CaM; CaM that had been boiled at alkaline $\mathrm{pH}$ or rendered non-functional during the rhodamine labeling does not show spindle association (fig. $3 \mathrm{~b}$ ).

The mitotic localization described here corroborates the immunofluorescent pattern seen by others. We did not, however, see the prominent mitochondrial $[19,40]$ or stress fiber localization $[31,40]$ in interphase cells that has been observed with immunofluorescence or by binding CaM-RITC to fixed cells. Our observations are, however, consistent with the ultrastructural localizations of 
CaM recently reported by Willingham et al. [41]. Several possibilities may explain the differences in the results from different methods. In our interphase cells the cytoplasm is generally bright so that a small CaM concentration difference between particular structures and the surrounding cytoplasm might be obscured. The fixation protocols used in the other studies may have enhanced these differences in concentration by washing out "soluble" CaM. Alternatively the injected CaM may not readily replace endogenous $\mathrm{CaM}$ in mitochondria and stress fibers. Finally, it is possible that these localizations previously described are a result of some preparative modification of the cell for light microscopy which induces non-physiological CaM binding.

We did not observe any anomalies in the behavior of cells which had been injected with sufficient $\mathrm{CaM}$ approximately to double the intracellular $\mathrm{CaM}$ concentration. Hamaguchi \& Iwasa [18] also saw no alterations in development of urchin eggs which contained about 2.5 times the normal amount of CaM. Presumably this is because the cell is maintaining intracellular calcium concentrations at a low level, so that the addition of extra CaM simply increases the pool of inactive $\mathrm{CaM}$ in the cell. The injection of affinity-purified antibody to $\mathrm{CaM}$ also failed to affect the ability of mitotic cells to divide. It should be pointed out, however, that our assays would not have detected subtle changes in chromosome behavior or rates of movement, only a blockage or significant slowing of movement. Further, since the antibody used was not a precipitating antibody, it may simply have bound inocuously to a portion of the CaM molecule. Finally, while we injected enough antibody to bind essentially all of the cell's CaM, some fraction of the $\mathrm{CaM}$ in vivo may be situated so as to block binding or some fraction of the antibody may be inactive in vivo. We cannot conclude that CaM is irrelevant for mitosis.

The most striking findings of the mitotic injection studies are the rapidity with which $\mathrm{CaM}$ is concentrated in the spindle and the fact that $\mathrm{CaM}$ can be added to the spindle at any time in the mitotic cycle. Since we introduce an average of $1.5 \times 10^{-13}$ liter per cell, the protein concentration range injected $(0.1-1 \mathrm{mg} / \mathrm{ml})$ means that the CaM level in the injected cells is elevated 6.5-65\% (assuming 0.15-0.27 pg CM per cell [41]). Given that the injection of $0.1 \mathrm{mg} / \mathrm{ml} \mathrm{CaM-RITC}$ gave results qualitatively identical to those observed with the $1 \mathrm{mg} / \mathrm{ml}$ concentration, the rapid recruitment of CaM to the spindle is not likely to be an artefact of the high concentrations of CaM injected. We cannot rule out the possibility, however, that even a 5-10\% increase in CaM levels would affect an equilibrium between CaM bound in the spindle and that free in the rest of the cell.

The CaM-RITC we have utilized has a distinct advantage over the DACM-CaM described by Hamaguchi \& Iwasa [18]. Because the rhodamine excitation maximum is in the green, cells are less damaged by observation than with the near UV excitation needed for DACM. This eliminates background fluorescence from cellular components and permits prolonged observation of single cells. This fact has allowed us to observe the transition in position of CaM which occurs at 
anaphase and should allow one to monitor the effects of substances such as calcium, stelazine, or antibodies, on CaM location and function.

Our observations suggest the possibility of experimentally exchanging endogenous CaM, either in vivo or in lysed cell models, with CaM modified by crosslinking reagents [42]. This type of experiment may allow one to determine the near neighbors of $\mathrm{CaM}$ in the spindle and in so doing, to provide an indication of the molecules and processes that $\mathrm{CaM}$ regulates in the mitotic spindle.

This work was supported by grants from the NIH (GM 30213 to J.R.M., and HD 15246 to M.J.W.) and the ACS (CD8 to J.R.M. and IN 40V to the University of Michigan and J.I.W.). The equipment for microinjection was purchased in part through a Biomedical Research Support Grant to the University of Colorado and through a gift from Colorado Video, Inc.

\section{REFERENCES}

1. Means, A R, Tash, J S \& Chafouleas, J G, Physiol rev 62 (1982) 1.

2. Cheung, W Y, Science 207 (1980) 19.

3. Klee, C B, Crouch, T H \& Richman, P G, Ann rev biochem 49 (1980) 489.

4. Welsh, M J, Dedman, J R, Brinkley, B R \& Means, A R, Proc natl acad sci US 75 (1978) 1867.

5. Andersen, B, Osborn, M \& Weber, K, Cytobiologie 17 (1978) 354.

6. Welsh, M J, Dedman, J R, Brinkley, B R \& Means, A R, J cell biol 81 (1979) 624.

7. Marcum, J M, Dedman, J R, Brinkley, B R \& Means, A R, Proc natl acad sci US 75 (1978) 3771.

8. Sobue, K, Fujita, M, Muramoto, Y \& Kakiuchi, S, FEBS lett 132 (1981) 137.

9. Abe, T \& Saisu, H, Biomed res 3 (1982) 207.

10. Job, D, Fischer, E \& Margolis, R L, Proc natl acad sci US 78 (1981) 4679.

11. Yagi, K, Yazawa, M, Kakiucki, S, Ohshima, M \& Uenishi, K, J biol chem 253 (1978) 1338.

12. Dabrowska, R, Sherry, J M, Aromatorio, D K \& Hartshorne, D J K, Biochemistry 17 (1978) 253.

13. Guerriero, V, Rowley, D R \& Means, A R, Cell 27 (1981) 449.

14. Glenney, J, Glenney, P, Osborn, M \& Weber, K, Cell 28 (1982) 843.

15. Sobue, K, Morimoto, K, Kanda, K, Maruyama, K \& Kakiuchi, S, FEBS lett 138 (1982) 289.

16. Blum, J J, Hayes, A, Jamieson, G \& Vanaman, T C, J cell biol 87 (1980) 386.

17. Jamieson, G A , Vanaman, T C \& Blum, J J, Proc natl acad sci US 76 (1979) 6471.

18. Hamaguchi, Y \& Iwasa, F, Biomed res 1 (1980) 502.

19. Pardue, R L, Kaetzel, M A, Hahn, S H, Brinkley, B R \& Dedman, J R, Cell 23 (1981) 533.

20. Welsh, M J, Aster, J, Ireland, M, Alcala, J \& Maisel, H, Science 216 (1982) 642.

21. Graessmann, A, Graessmann, M \& Mueller, C, Meth enzymol 65 (1980) 816.

22. Miyachi, Y, Vaitukaitis, J, Nieschlag, E \& Lipsett, M B, J clin endocrinol metabolism 34 (1972) 23.

23. Schlegel, R \& Rechsteiner, M, Cell 5 (1975) 371.

24. Chafouleas, J G, Dedman, J R, Munjaal, R P \& Means, A R, J biol chem 254 (1979) 10262.

25. Dedman, J R, Potter, J D, Jackson, R L, Johnson, J D \& Means, A R, J biol chem 252 (1977) 8415.

26. Filburn, C R \& Karn, J, Anal biochem 52 (1973) 505.

27. Cheung, W Y, J biol chem 246 (1971) 2859.

28. Nairn, R C, Fluorescent protein tracing. Churchill Livingston, Edinburgh, London and New York (1976).

29. Taylor, D L, Reidler, J, Spudich, J A \& Stryer, L, J cell biol 89 (1981) 362.

30. Bradford, M, Anal biochem 72 (1976) 248.

31. Zieve, G, Turnbull, D, Mullins, J M \& McIntosh, J R, Exp cell res 126 (1980) 397.

32. Van Eldik, L J \& Watterson, D M, J biol chem 256 (1981) 4205.

33. Dedman, J R, Welsh, M J \& Means, A R, J biol chem 253 (1978) 7515.

34. Klee, C, Biochemistry 16 (1977) 1017.

35. Stacey, D W \& Allfrey, V G, J cell biol 75 (1977) 807.

36. Kreis, T \& Birchmeier, W, Int rev cytol 75 (1982) 209.

37. Wang, K, Feramisco, J R \& Ash, J F, Meth enzymol 85 (1982) 514. 
38. Wang, Y-L, Heirple, J M \& Taylor, D L, Meth cell biol 25 (1982) 1.

39. Wang, Y-L \& Taylor, D L, J cell biol 81 (1979) 672.

40. Pardue, R L, Perry, G W, Brady, R C \& Dedman, J R, J cell biol 96 (1983) 1149.

41. Willingham, M C, Wehland, J, Klee, C, Richert, N, Rutherford, A \& Pastan, I, J histochem cytochem 31 (1983) 445.

42. Chafouleas, J G, Pardue, R L, Brinkley, B R, Dedman, J R \& Mcans, A R, Proc natl acad sci US 78 (1981) 996.

43. Andreasen, T J, Keller, C H, LaPorte, D C, Edelman, A M \& Storm, D R, Proc natl acad sci US 78 (1981) 2782 .

Received June 2, 1983

Revised version received June 30, 1983

Printed in Sweden 